\title{
Effects of mechanical properties and geometric conditions on stiffness of Hyperboloid Shallow Shell
}

\author{
Lihong Zhao ${ }^{1, a}$, Haiping $\mathrm{Yu}^{2}$, Zhongwen Xing ${ }^{3}$, and Chengxi $\mathrm{Lei}^{3}$ \\ ${ }^{1}$ Engineering Training Center, Harbin Engineering University, Heilongjiang Harbin, China \\ ${ }^{2}$ School of Materials Science and Engineering, Harbin Institute of Technology, Heilongjiang Harbin, \\ China \\ ${ }^{3}$ School of Mechatronics Engineering, Harbin Institute of Technology, Heilongjiang Harbin, China
}

\begin{abstract}
The experiment models based on the hyperboloid shallow shells that represent automobile panel's surface features are established. The effects of material properties and geometric conditions condition on the stiffness of hyperboloid shallow shell are investigated experimentally. The influences of panel thickness and geometric conditions on stiffness are very obvious. Stiffness increases with increasing of the panel thickness, and stiffness doubled as increasing in thickness with $0.1 \mathrm{~mm}$. The effect of thickness on stiffness is far greater than that of blank holding force. The greater the arc height of punch, the greater the stiffness. And stiffness increases nearly by five times with arc height of punch is from $3 \mathrm{~mm}$ to $9 \mathrm{~mm}$. The effect of arc height of punch on stiffness is far greater than that of materials mechanical properties. The stiffness is varied with different panel material properties by the same forming and stiffness test conditions. The decrease of yield strength is beneficial to the panel stiffness. The appropriate choice of materials and forming process condition is important in meeting necessary requirements for the energy-saving, lightweight and reducing wind resistance design in automotive industry.
\end{abstract}

\section{Introduction}

Lightweight technology has become one of the main development directions in automobile industry for the energy-saving, environmental protection, low cost and material saving. This trend promotes many lightweight, high strength steels and other new materials are introduced into the automobile manufacturing [1-6]. First, flat shape of car body in the automobile structure design and the thickness of covering parts are taken into account in views of reducing wind resistance and energy saving. Then, we pay more attention to the effects caused of this on the performance of automobile, such as one of these effects of automotive panel stiffness [7]. There is great correlation between the stiffness and the security, even the performance of the automobile. Lots of relevant research works have been done with the experiment and numerical simulation methods about panel stiffness problems, especially by means of shallow shell [8-10]. Many research achievements are obtained, such as the effects of parts geometry,

\footnotetext{
${ }^{\text {a }}$ Corresponding author: zhaolihong007@163.com
}

This is an Open Access article distributed under the terms of the Creative Commons Attribution License 4.0, which permits unrestricted use, distribution, and reproduction in any medium, provided the original work is properly cited. 
Table 1. Mechanical properties of materials.

\begin{tabular}{|c|c|c|c|c|}
\hline Material & $\sigma_{s}[\mathrm{Mpa}]$ & $E[\mathrm{Mpa}]$ & $\sigma_{b}[\mathrm{Mpa}]$ & $\delta[\%]$ \\
\hline $1^{\#}$ & 235 & $2.07 \times 10^{5}$ & 500 & 26 \\
\hline $2^{\#}$ & 280 & $2.07 \times 10^{5}$ & 410 & 28 \\
\hline $3^{\#}$ & 135 & $2.07 \times 10^{5}$ & 280 & 37 \\
\hline
\end{tabular}

Table 2. Punch size parameters [mm].

\begin{tabular}{|c|c|c|c|c|c|}
\hline$R 1$ & $R 2$ & Length & Width & Corner radius & Profile radius \\
\hline 1200 & 1000 & 300 & 280 & 5 & 35 \\
\hline
\end{tabular}

material properties parameters, forming process parameters and springback of single curved surface shell (cylindrical shallow shell) [11, 14]. But, the sag depression of the deflection after the forming, spring and stiffness loading of the doubly curved flat shell (hyperboloid Shallow Shell) is different with cylindrical shallow shell'. It is a very complicate geometric nonlinear problem.

In order to develop a comprehensive understanding on the stiffness of automobile, large numbers of experiments are performed in this work to study the influences mechanical properties and geometric conditions, such as thickness and arc height on the stiffness of hyperboloid shallow shells of the automobile panel. All conclusions provided a technical approach in the automobile panel production.

\section{Experiments}

Many automobile panels have the features of hyperboloid shallow shells, such as car roof, engine hood and door. Therefore, the experimental model of hyperboloid shallow shell is introduced here to study the stiffness of automobile panel, which with characteristics of double curved that its surface is designed by one circular arc moves along the other circular arc segment. In order to expand the research on stiffness, the shells forming experiment, springback and stiffness loading test are obtained with different geometrical and material conditions.

\subsection{Experimental materials}

Three kinds of materials were used in this experiment research work. The basic mechanical properties of the materials of cold-rolled steel are given in Table 1. Where $E$ is Young's modulus, $\sigma_{s}$ is the yield strength, $\sigma_{b}$ is tensile strength and $\delta$ is elongation. Material $1^{\#}$, thickness is respectively $0.5 \mathrm{~mm}, 0.6 \mathrm{~mm}$, $0.8 \mathrm{~mm}$; material $2^{\#}$, thickness is respectively $0.5 \mathrm{~mm}, 0.6 \mathrm{~mm}, 0.7 \mathrm{~mm}$; material $3^{\#}$, thickness is $0.5 \mathrm{~mm}$.

\subsection{Experimental process}

\subsubsection{Hyperbolic shallow shell forming}

The forming punch parameters of hyperbolic shallow shell are shown in Table 2. The hyperboloid shallow shell (Fig. 1) were drawn with $2000 \mathrm{kN}$ double-acting sheet hydraulic press, in which blank holding force (BHF) can be regulated steplessly. In this experiment, the dimensions of rectangle blanks, drawing depth and lubricating were determined to $400 \mathrm{~mm} \times 300 \mathrm{~mm}, 16 \mathrm{~mm}$ and machine oil respectively. 


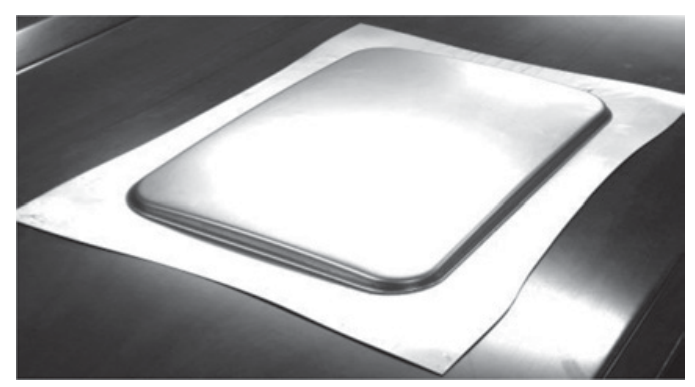

Figure 1. Hyperboloid shallow shell after forming.

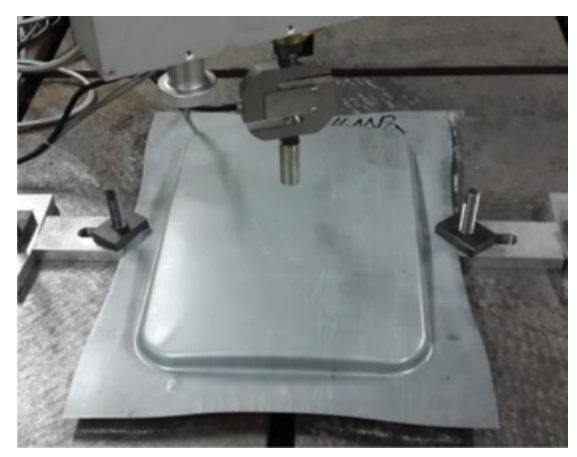

Figure 2. Portable stiffness tester.

\subsubsection{Stiffness test}

The stiffness test is performed after the forming of shallow shell with the portable stiffness tester (Fig. 2). The shell is loaded with the indenter and displacement is measured continuously during the loading. The stiffness evaluation is based on the method of initial point slope [11].

\section{Experimental results and analysis}

Analyses of parts geometry and material properties on the automotive panel stiffness are investigated, which can provide theoretical and practical basis to improve the automotive panel stiffness.

\subsection{Effects of parts geometry condition on stiffness}

The effects of parts geometry condition on stiffness are analysis, such as, panel thickness and arc height of punch.

\subsubsection{Effects of panel thickness}

Two kinds of materials $1^{\#}$ and $2^{\#}$ are introduced here to investigate the influence law of panel thickness on stiffness. The thickness of material $1^{\#}$ is $0.5 \mathrm{~mm}, 0.6 \mathrm{~mm}$ and $0.8 \mathrm{~mm}$ respectively, material $2^{\#}$ includes three kinds of thickness, $0.5 \mathrm{~mm}, 0.6 \mathrm{~mm}$ and $0.7 \mathrm{~mm}$. The relations between the thickness and stiffness of materials $1^{\#}$ and $2^{\#}$ with different BHF are shown in Fig. 3 and Fig. 4 respectively.

As can be observed from Fig. 3 and Fig. 4, the effect of panel thickness on stiffness is very obvious. It almost shows a linear relationship that stiffness increases with increasing of the panel thickness, and the rate of increase is nearly in double with panel thickness increased in $0.1 \mathrm{~mm}$. Another effect of forming process that BHF on stiffness is emerged clearly that stiffness is increase with increasing of BHF (from 1.6 MPa to 2.4 MPa). Three kinds of materials all come to the same conclusion above. Then, the effect of thickness on stiffness is far greater than that of BHF in forming limit range.

\subsubsection{Effects of arc height of punch}

Three kinds of materials, $4^{\#}, 5^{\#}$ and $6^{\#}$ are introduced here to investigate the influence law of arc height of punch on stiffness. The basic mechanical properties of three kinds of materials are given in Table 3 . The thickness of these materials is the same as $0.8 \mathrm{~mm}$. In this experiment, the dimensions of rectangle blanks, drawing depth and lubricating were determined to $415 \mathrm{~mm} \times 315 \mathrm{~mm}, 20 \mathrm{~mm}$ and machine oil 


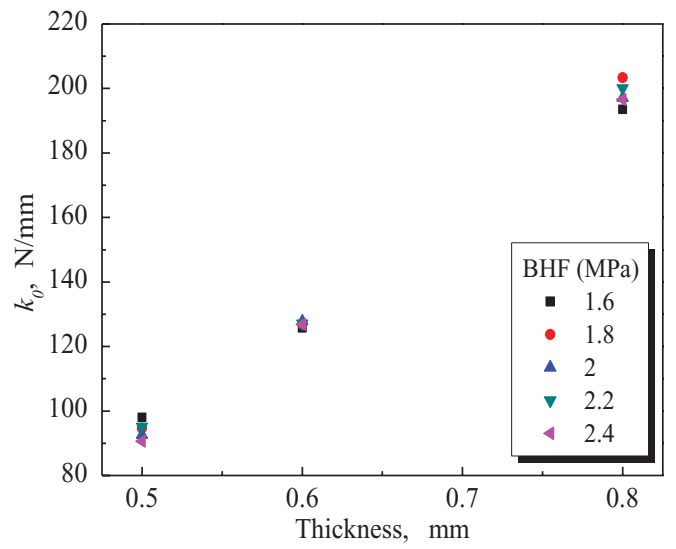

Figure 3. Relation between panel thickness and stiffness of $1^{\#}$.

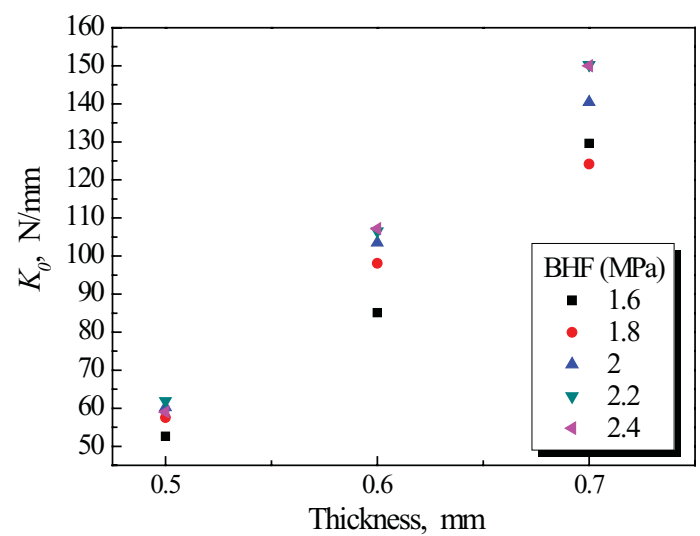

Figure 4. Relation between panel thickness and stiffness of $2^{\#}$.

Table 3. Mechanical properties of materials 2.

\begin{tabular}{|c|c|c|c|c|c|}
\hline Material & $E(\mathrm{MPa})$ & $\mu$ & $\sigma_{\mathrm{S}}(\mathrm{MPa})$ & $N$ & $r$ \\
\hline $4^{\#}$ & $2.07 \times 105$ & 0.3 & 185 & 0.22 & 1.91 \\
\hline $5^{\#}$ & $2.07 \times 105$ & 0.3 & 162 & 0.23 & 2.21 \\
\hline $6^{\#}$ & $2.07 \times 105$ & 0.3 & 157 & 0.25 & 2.36 \\
\hline
\end{tabular}

respectively. The dimensions of width and length of punch are $150.5 \mathrm{~mm}$ and $242.5 \mathrm{~mm}$, and the arc height of punch is $3 \mathrm{~mm}, 6 \mathrm{~mm}, 9 \mathrm{~mm}$ respectively. The blank holding force of forming is $320 \mathrm{kN}$.

Figure 5 shows the relation between the arc height of punch and the stiffness with three kinds of materials. The effect of arc height of punch on the stiffness is very obvious. The greater the arc height of punch, the greater the stiffness. Stiffness is increased nearly by five times with arc height of punch is from $3 \mathrm{~mm}$ to $9 \mathrm{~mm}$, and it shows that the effect of arc height on stiffness is very prominent also. Another result is obtained that the stiffness is changed with different materials from the Fig. 5. It can be concluded that materials mechanical properties has an impact on stiffness, but the effect of arc height of punch on stiffness is far greater than that of materials mechanical properties. 


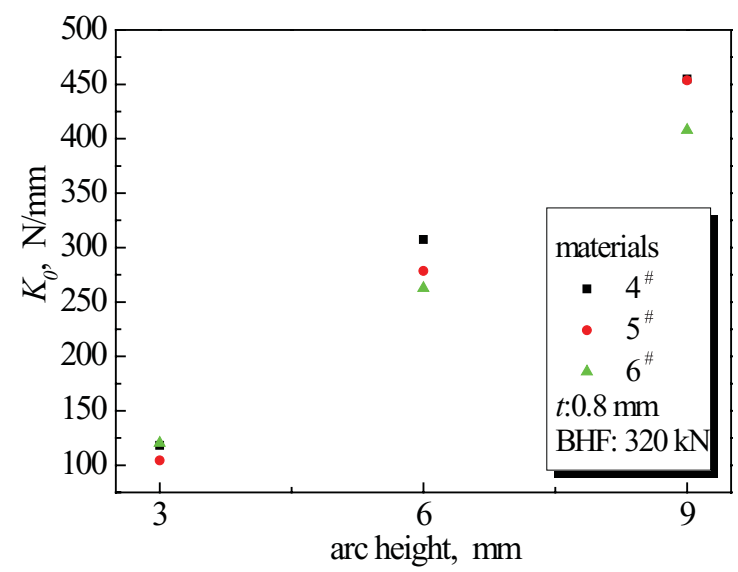

Figure 5. Relation between arc height of punch and stiffness.

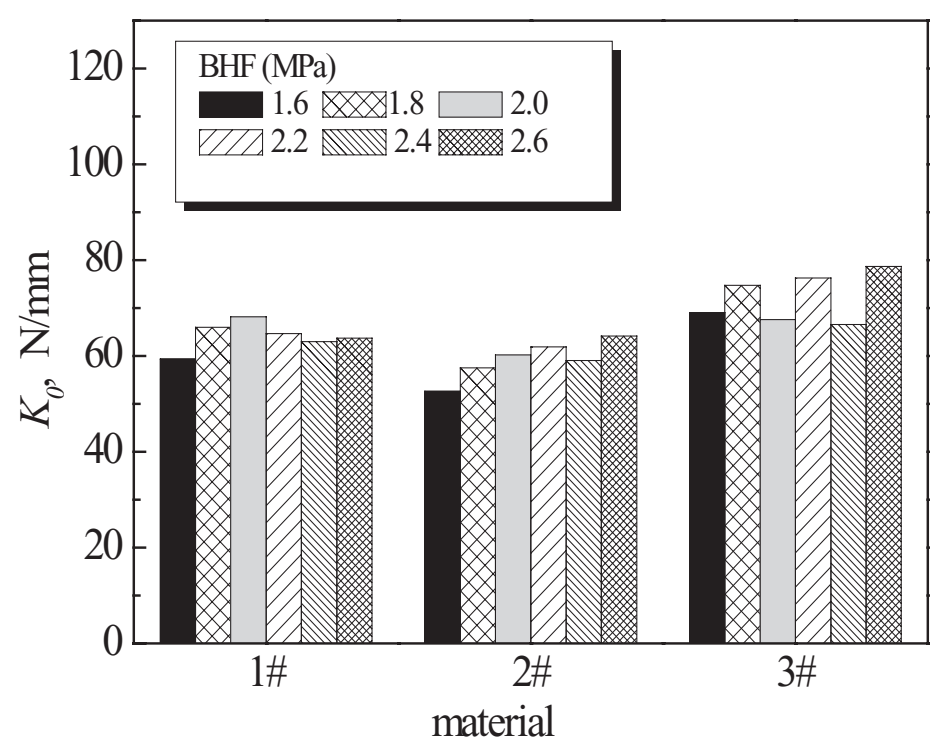

Figure 6. Relation between mechanical properties of materials and stiffness.

\subsection{Effects of mechanical properties on stiffness}

Three kinds of materials, $1^{\#}, 2^{\#}$ and $3^{\#}$ are introduced here to investigate the material mechanical properties on stiffness of hyperboloid shallow shells. The shells are forming with same BHF and drawing depth $(30 \mathrm{~mm})$ respectively. The thickness of three materials is the same as $0.5 \mathrm{~mm}$. Figure 6 shows the stiffness of three materials with BHF 1.6 MPa, 1.8 MPa, 2 MPa, 2.2 MPa and 2.4 MPa.

Figure 6 shows that stiffness is different with three kind materials, even the little difference is found under different BHF. So, effect of materials on stiffness is complicate. The stiffness of material $3^{\#}$ is greater than others, and stiffness of material $1^{\#}$ is slightly greater that that of material $2^{\#}$. The yield strength $\sigma_{s}$ of material $3^{\#}$ is smallest among the three kinds of materials, and $\sigma_{s}$ of material $2^{\#}$ is largest (Table 1). It can be concluded that the effect of $\sigma_{s}$ on the stiffness is obvious in the mechanical properties 


\section{MATEC Web of Conferences}

for the great difference of $\sigma_{s}$, although the effect of interaction of mechanical properties of materials on the stiffness can not be ignored.

\section{Summary}

The experiment study models of which based on the hyperboloid shallow shells that could represent automobile panel surface features is established. The experiment research works of effects of material properties and geometric conditions condition on the stiffness of hyperboloid shallow shell are obtained. The influences of panel thickness and geometric conditions on the stiffness are very obvious. The stiffness increases with increasing of the panel thickness. The thicker the sheet thickness, the greater the panel stiffness, and stiffness doubled as increasing in thickness with $0.1 \mathrm{~mm}$. The effect of thickness on stiffness is far greater than that of BHF. The greater the arc height of punch, the greater the stiffness. And stiffness increases nearly by five times with arc height of punch is from $3 \mathrm{~mm}$ to $9 \mathrm{~mm}$. The effect of arc height of punch on stiffness is far greater than that of materials mechanical properties. The stiffness is different with different panel material properties by the same experimental conditions. From the results of the investigation, the decrease of yield strength is beneficial to the panel stiffness. The lower the yield strength value, the greater the stiffness. The appropriate choice of material is important in meeting necessary requirements for the energy-saving, low cost with lightweight and reducing wind resistance design in automotive industry. Of course, the forming process condition is too effective to be ignored to improve the stiffness.

The authors acknowledge the support from the National Natural Science Foundation of China (51275103).

\section{References}

[1] A. Kastensson, J. Clean. Prod, 66 (2014)

[2] N. Sakundrini, Z. Taha, S. Hanim A. Rashid, R.A.R.Ghazila, Mater. Des, 50 (2013)

[3] R.Dhingra, S.Das, J. Clean. Prod, 85 (2014)

[4] A.T. Mayyas, A. Qattawi, A.R. Mayyas, M. Omar, J. Clean. Prod, 40 (2013)

[5] A. Mayyas, A. Qattawi, M. Omar, D. Shan, Renew. Sust. Energ. Rev, 16 (2012)

[6] A.A. Zorpas, V.J. Inglezakis, Technology in Society, 34 (2012)

[7] N. Asnafi, J. Mater. Process. Technol, 49 (1995)

[8] S. Holmberg, P. Thilderkvist, Mater. Des, J. 23 (2002)

[9] S. Holmberg, B. Nejabat, Mater. Des, J. 25 (2004)

[10] E. Evin, M. Tomas, J. Kmec, S. Nemeth, Procedia Engineering, 69 (2014)

[11] L.H. Zhao, Z.Z. Sun, Y.Y. Yang, J. Mater. Process. Technol, 187-188 (2007)

[12] L.H. Zhao, S.Y. Jiang, Z.Y. Ren. Int. J. Mod. Phys. C, 23 (2009)

[13] Z.W. Xing, L.L. Zhao, Y.Y. Yang, Chinese Journal of Mechanical Engineering, 44 (2008)

[14] L.H. Zhao, S.Y. Jiang, Z.W. Xing, Y.Q. Zhang, Mater. Sci. Technol, 20 (2012) 